Article

\title{
Exploring Public Opinions on Renewable Energy by Using Conventional Methods and Social Media Analysis
}

\author{
Istvan Ervin Haber ${ }^{1, *(\mathbb{D}}$, Mate Toth ${ }^{2}$, Robert Hajdu ${ }^{2}$, Kinga Haber ${ }^{2}$ and Gabor Pinter $^{3}$ \\ 1 Energia Design Research Group, Szentagothai Research Center, University of Pecs, H-7622 Pécs, Hungary \\ 2 Ad-Vitalis Ltd., H-7624 Pecs, Hungary; mate.toth@advitalis.hu (M.T.); robert.hajdu@advitalis.hu (R.H.); \\ kinga.haber@advitalis.hu (K.H.) \\ 3 Smart-Inno Expert Ltd., H-8360 Keszthely, Hungary; gabor.pinter@smartinno.hu \\ * Correspondence: ihaber@mik.pte.hu
}

Citation: Haber, I.E.; Toth, M.; Hajdu, R.; Haber, K.; Pinter, G. Exploring Public Opinions on Renewable Energy by Using Conventional Methods and Social Media Analysis. Energies 2021, 14, 3089. https:// doi.org/10.3390/en14113089

Academic Editor:

Dimitrios Katsaprakakis

Received: 16 April 2021

Accepted: 24 May 2021

Published: 26 May 2021

Publisher's Note: MDPI stays neutral with regard to jurisdictional claims in published maps and institutional affiliations.

Copyright: (c) 2021 by the authors. Licensee MDPI, Basel, Switzerland. This article is an open access article distributed under the terms and conditions of the Creative Commons Attribution (CC BY) license (https:// creativecommons.org/licenses/by/ $4.0 /)$.

\begin{abstract}
Renewable energy is one of the most discussed topics nowadays, more so than traditional combustible energy sources and nuclear energy. There is an apparent need to study its public acceptance and the general public's knowledge about it, especially in the context of more advanced inventions, such as smart grids, energy storage, or photovoltaic inverters. In this research, the results of a custom survey and those of several types of public social media datasets were processed to gain insights into the acceptance and awareness of these technologies. The second aim was to investigate technologies and related public opinions about manufacturers. One social media dataset was processed by a novel technology based on automatic data collection from popular social media sources, blogs, forums and public news. All the collected and anonymized data were restored in a custom-made data lake (unstructured database) and analyzed by a natural language processing (NLP) engine to extract the required information. The results showed that the Hungarian public's knowledge differs from the European reference values by a very high percentage. A further goal for new research in the investigated area will be to achieve a business intelligence rated system in order to predict future trends and events. Since different methods provide results from different viewpoints, the conclusion is that combined analyses have to be used for investigating popular topics related to energy, such as various technologies, issues related to energy transition, or even car sharing services for a sustainable future.
\end{abstract}

Keywords: social media analysis; NLP; energy; renewable energy; energy transition; public opinion

\section{Introduction}

Renewable energy sources (RESs) are becoming an increasingly important part of the energy mix in the European Union (EU). Their presence in the overall energy mix of European countries has been constantly rising for the last thirty years; therefore, it is important to know the extent of the public acceptance of these technologies. The utilization of renewable energy shows great variation in the EEA Member States. While its penetration is very high in some states (Norway: $72.752 \%$, Iceland: $72.128 \%$ ), it is markedly low in other member states (the Netherlands: $7.385 \%$, Malta: $7.978 \%$ ). Hungary $(12.489 \%)$ is also among the nations with lower penetrations according to 2018 data [1]. The status of renewable energy sources in a given country depends on several factors, such as economic resources, the availability of renewable resources and acceptance. From the above countrylevel data, it is clear that the use of these resources does not necessarily depend on the country's economic performance (GDP), but it is clear that there is a "gap" between northern, southern and eastern European countries [2]. This article explores the reasons for this from the perspective of public acceptance by using social media analysis and a public survey, which are considered to be useful tools for such a purpose [3,4], since they can provide a deep insight into people's opinions on a given topic. 
A study from the Czech Republic [5] shows that a public survey can show citizens' opinions on renewables as electricity resources (RES-E); however, it also states that more research is needed in this field. Nevertheless, social acceptance is regarded as one of the most important requirements for the successful adoption of any technology-for instance, energy infrastructure technologies. The example of Spain shows [6] that, despite dynamic growth in the RES sector, the mass media are capable of generating negative opinions concerning the RESs as well as achieving a higher public acceptance of nuclear energy at the same time. It seems that if a national strategy for climate protection and energy [7] names nuclear energy as the most important part of the energy mix (for energy security reasons), social acceptance can be created artificially. A study in Portugal [8] on RES acceptance does not include nuclear sources; however, with a deeply sophisticated statistical method, conclusions can be derived for the entire field.

Studies on the photovoltaics (PV) market show that the issues regarding its social and public acceptance have largely been neglected in the literature, perhaps due to the particularly positive public opinion that has tended to prevail with this source of energy $[6,9,10]$. However, it must not be forgotten that this industry also has a dark side when the carbon footprint related to manufacturing and recycling is considered.

One way to change the above situation is to explore the leading social media platforms (Facebook, Twitter, etc.) by data mining tools. As the relevant data traffic of the last more than 10 years has taken place on these platforms, this method can provide a good picture of the opinions in a given country or region. In terms of data processing, gender and sentiment-based classifications can be used to obtain a more nuanced picture of the gender distribution of opinions, while sentiment analysis gave polarity to the social media dataset, which in turn allows the analysis of the data used. The data obtained in this way were molded into a comprehensible form by means of data visualization, and thus conclusions could be drawn from them for analysis. The other tool-which is also a very common method according to the scholarly literature-was the questionnaire which delivered the data that were also analyzed using data visualization.

The aims of this study are to (i) compare RES opinion results with other EU member states, (ii) to show more advanced technologies based on social media data collection and to introduce a standard method for data collection and processing.

\section{Public Opinion about RESs in Hungary}

The initial research method was based on previous scientific work where a survey was executed in the Czech Republic [5]. To be comparable, the same questions were asked in an online survey in Hungary, where 716 respondents gave feedback. According to the correspondence of the samples with the total population in quotes, the data sample appears to be representative for Hungary, which would ensure at least a confidence interval of $95 \%$ with a margin of error of $4 \%$ [9]. The data is deposited by the authors at the following address: https:/ / docs.google.com/forms/d/1hpM4pJgqs6Etf1eIB27mq4aj-BKwgadsW6 _gj6XV0Bs / (accessed on 11 May 2020).

The age distribution of respondents was as follows: aged 15 to $24: 13.82 \%, 25-34$ $34.1 \%, 35-44: 34.56 \%, 45-54: 12.44 \%$, and the rest were aged 55 or above. As for their genders, $42.7 \%$ of the participants were women and $57.3 \%$ were men.

\subsection{Measures of Opinions on RES}

The sample questionnaire surveyed whether the respondents believed it was possible to replace the conventional sources of energy production with renewable energy ones. The exact question (Q1) was the following: "Do you think it is possible to replace electricity generation from the conventional sources (such as coal-fired or gas-fired power plants, nuclear power plants or large hydroelectric power plants) by generating electricity from wind, solar radiation, and biomass combustion?" (1-it is definitely possible to replace it, 2-it is rather possible to replace it, 3-it is rather not possible to replace it, 4-it is definitely not possible to replace it). The answer distribution is shown in Figure 1. 


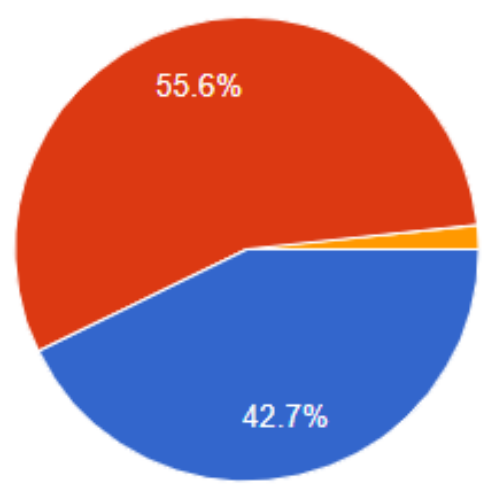

1. (definitely possible to replace it)

2. (rather possible to replace it)

3. (rather not possible to replace it)

Figure 1. The distribution of the answers about the possibility of replacing conventional energy sources.

The next question was concerned with the renewables in the country's use (Figure 2.): "What do you think the situation is in our country concerning the use of renewable energy sources?" (1-very good, 2-rather good, 3-rather bad, 4-very bad).
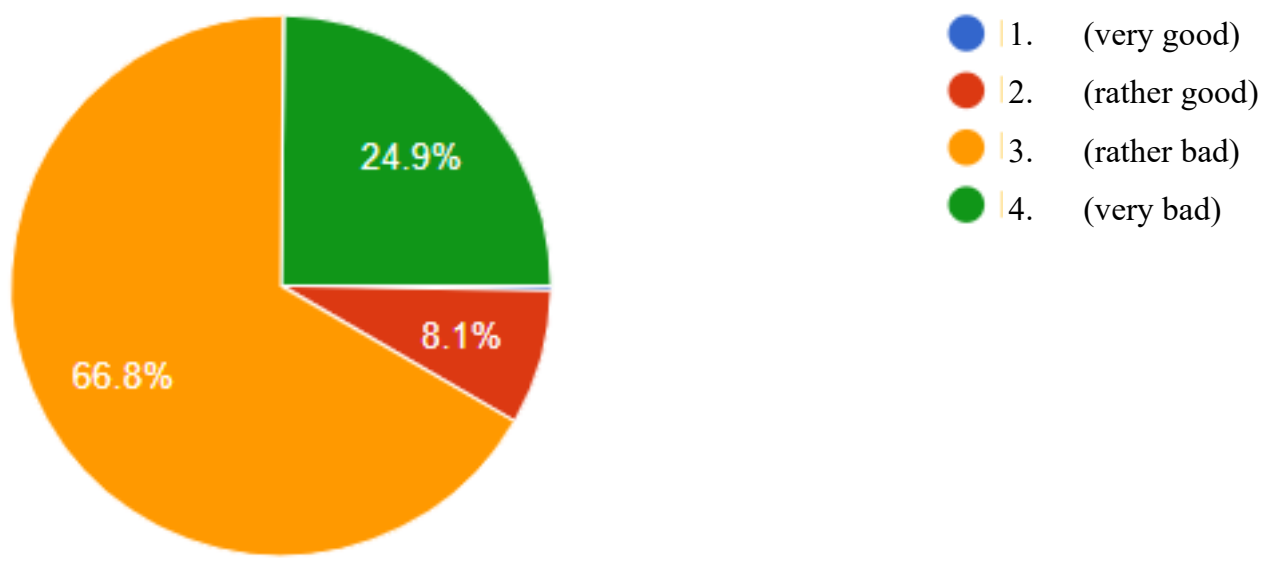

Figure 2. The distribution of the answers regarding the country's use of RESs.

In comparison with the previous Czech research [5], the answers given to Q1 (question No. 1) showed a significant difference in the opinions. According to the answers of the Hungarian respondents, more than $55 \%$ believed that conventional sources are replaceable with RES, while in the Czech Republic it was only 30\%. Regarding Q2, only $8.1 \%$ of the Hungarian participants gave positive answers, in comparison with the other country's value of $45 \%$.

\subsection{Measures of Opinions on the Environment}

The next group of questions $(\mathrm{Q} 3, \mathrm{Q} 4, \mathrm{Q} 5)$ were designed to measure opinions related to the environment. Q3 was about the Hungarian government's responsibility for the environment, i.e., whether the government takes responsibility for it in a transparent way or not (Figure 3). The answers were quite different from the Czech ones, since the Hungarian respondent's opinion was that the government cares too little about it. This has some local reasons, mainly political, based on the country's limited land resources and the activity of privileged industrial and personal entities. The rating scale for this question had three levels (1-good level, 2-middle level, 3-lowest level) to express opinions on how the government looks after the environment. 


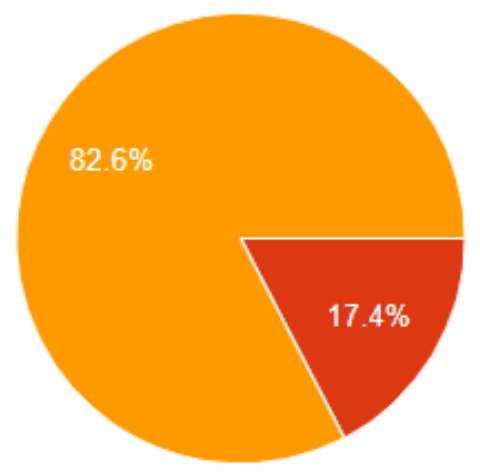

1. (good level)

2. (middle level)

3. (lowest level)

Figure 3. The distribution of the answers about howthe country takescare ofthe environment.

Q4 asked the respondents about their willingness to protect the environment by their personal behavior: "In your household, do you save energy and water for environmental reasons?" 1 -always, 4 -never, on a 4 -point scale. Here, $19.9 \%$ of the respondents chose answer 1 ("always"), 43.9\% answer 2, 21.8\% answer 3 ("rather no") and 4.5\% selected "absolutely not".

Q5 was "Do you have enough information on the state of the environment in Hungary?", with the same scale as that of Q4. The received answers are showing the following distribution: $1-12.9 \%, 2-30.8 \%, 3-38.1 \%, 4-18.2 \%$. The compared results are shown in Table 1.

Table 1. Compared results for Q4 andQ5 [5].

\begin{tabular}{lcccc}
\hline \multicolumn{1}{c}{ Answer } & Good & Rather Good & Rather Bad & Bad \\
\hline Q4 Hungary & $19.90 \%$ & $43.90 \%$ & $21.80 \%$ & $4.50 \%$ \\
Q4 Czech & $19.20 \%$ & $42.70 \%$ & $24.50 \%$ & $12.20 \%$ \\
Republic & $12.90 \%$ & $30.80 \%$ & $38.10 \%$ & $18.20 \%$ \\
Q5 Hungary & $2.30 \%$ & $35.70 \%$ & $45.30 \%$ & $10.20 \%$ \\
Q5 Czech & & & \\
Republic & & & & \\
\hline
\end{tabular}

\subsection{Measure of the Worry about the Use of Nuclear Energy}

The worry about the use of nuclear energy was also measured (Q6). Although it is named a zero emission solution alternative to RES, it has some well-known risks. Nuclear energy is considered as a means of increasing the energy securityof a country, but its public acceptance has greatly decreased since Fukushima [11]. The survey showed that 56.6\% of the Hungarian respondents were relatively unworried or not worried at all, which is lower than the $63 \%$ in the case of the Czech Republic. In Hungary, this is an important issue due to the Paks2 nuclear power plant project, which is currently under development, although the construction has not started yet. It is communicated by the government as a final decision, which has to be realized. Based on our survey, $25.4 \%$ of the respondents were absolutely worried about the use of nuclear energy, compared to the Czech Republic, where this proportion was only $6.9 \%$.

\subsection{Measures of Opinion on Living Standard and Life Satisfaction}

"Given that renewables are costly and present a relatively new technology, standard of living and life satisfaction of the respondents are the other two factors to consider. Both of them are related to the level of anxiety and fear of new things, which may substantially influence the acceptance of novel technologies. In addition, the standard of living proxies for the willingness to pay for the renewables as they are costly." [5]. Table 2 shows the results compared to the those of the study carried out in the Czech Republic. 
Table 2. Compared results for Q7 andQ8 [5].

\begin{tabular}{|c|c|c|c|c|c|}
\hline \multicolumn{6}{|c|}{ Life Satisfaction and Household Living Standard } \\
\hline \multicolumn{6}{|c|}{ Life satisfaction (Q7):1—very satisfied, 5—very unsatisfied } \\
\hline Hungary & $35.5 \%$ & $38.5 \%$ & $16.8 \%$ & $7.3 \%$ & $2.0 \%$ \\
\hline $\begin{array}{c}\text { Czech } \\
\text { Republic }\end{array}$ & $15.8 \%$ & $50.8 \%$ & $23.6 \%$ & $8.4 \%$ & $1.3 \%$ \\
\hline \multicolumn{6}{|c|}{ Household Living Standard (Q8):1—very good, 5—very bad } \\
\hline Hungary & $18.8 \%$ & $44.0 \%$ & $20.8 \%$ & $5.1 \%$ & $1.4 \%$ \\
\hline $\begin{array}{l}\text { Czech } \\
\text { Republic }\end{array}$ & $9.4 \%$ & $45.6 \%$ & $34.0 \%$ & $9.5 \%$ & $1.3 \%$ \\
\hline
\end{tabular}

In addition to the previous questions (which were adopted from a Czech survey [5]), others were also included to apply market research based on big data analyses for studying RESs. The aim was to explorethe knowledge of the wider public concerning technology. Based on these considerations, the public acceptance of the process of energy transition was examined first, followed by the awareness of technologies that are already commonly known.

Q9 and the following questions therefore were not part of the reference survey, but they were considered to preface Chapter 3, with more specified questions on technology. Q9 was phrased as follows: "Do you think our life has to be changed in connection with the energy transition?". The results for Q9 showed that $81.4 \%$ agreed that our lifestyle has to be changed mildly to dramatically $(48.1 \%$ and $33.3 \%)$ to achieve the aims of the transition. According to Q10, 79.6\% of the respondents were not using renewables, $13.3 \%$ had installed PV system and 5.6\% used thermal collectors in their households. In total, $19.9 \%$ of all respondents had been rewarded by some external fund for investing in energy efficiency, which included home isolation, the modernization/replacement of doors and/or windows, in addition to the use of RESs.

Q11 was concerned with identifying the energy source of the future, here were multiple choices possible. In total, $77.4 \%$ of all respondents named solar energy, $52.8 \%$ chose energy generation from waste, $51 \%$-wind, $43 \%$-geothermal, 30\%-fusion energy, while 20-20\% were for nuclear and biomass. It is well-known that Hungary has little potential for hydropower, so its share in the questionnaire answers was negligible.

Storing energy in amounts that can be considered relevant for residential purposes is a new area of research and development. However, it is also well-known, that the use of RESs can not be infinitely increased without in growth in electric energy storage capacities. Therefore, the survey covered the questions relating to if there was a general need to multiply the electric storage capacities at a large scale (more than $70 \%$ were of this opinion) and what the future technology could be for that purpose (Q12). In total, $35.2 \%$ of the respondents chose battery storage (multiple choices were allowed), 31.6\%-hydrogen based storage, $28.7 \%$-hydro storage, $14.2 \%$ selected methane or natural gas based storage, and $19.6 \%$ opted for electrolyte based systems. Smart grid solutions as decentralized systems were also an alternative option, with $30 \%$ of the respondents choosing it, which showedthat this was already a technology commonly known by the population too.

Finally, to connect the survey to the following topic in the second part of the research, it was also asked (Q13) if users would be willing to bear the extra cost of a hybrid PV inverter (which can be connected to an external battery system). It was revealed that more than $53 \%$ would pay $10 \%$ more on theprice if it is prepared for the coming situation where energy prices will be calculated hourly (it is not known yet when this will start, but some say within five years in Hungary).

The results showed in general, that the public acceptance for RESs in Hungary is higher than in Czech Republic (Q1), but the opinion about presumed use is lower (by Q2).

Classic public opinion collecting method based on open survey is a comparable method for international measurements [5]. In this referred article the conclusions have 
been made, that monitoring of social media channels could extend the recognition of opinions about RES. The public survey method has its limitation to find the persons and groups who use RESs and also care about the environment, if we need response for technology related questions. The following techniques can handle this weakness and can extend the classic method with standardized data collection and evaluation.

\section{Social Media Analysis Based on the Smap Works Big Data Ecosystem}

Big data and social media analysis for business intelligence is becoming more andmore accepted in commercial use. By means of surveys, it is almost impossible to find the people who use RESs in any form, as could be seen in the current survey, where the share of the respondents using RESs was only around $20 \%$. Targeted social media analyses, however, can identify exactly the users who own a specific product and-in an ideal case-even have an opinion about it. The acceptance of RESs [12], the opinions about a product related to RESs [13] and even the connection of RESs and climate change [14] can all be measured by big data sentiment analysis. There is no standardized solution for social media research, but it can be stated that the following steps are needed to perform a social media analysis:

1. Find data source and integrate data to own database:

Direct social media API access (Facebook, Twitter, TikTok, etc.);

Content provider who collects data from various sources (datastreamer, marketwatch, etc.);

Web crawling from related sources (blogs, forums, news sites and comments, etc.).

2. Extract quantitative data from text:

- Standard information collected by data provider as date, gender, geotag, age, etc.,

- Free text statistics collecting numbers and summarizing words for word cloud visualization.

3. Sentiment analysis with a standardized method;

4. Visualization.

\subsection{Solar Market Analysis}

Analyzing the inverter market can provide a good estimation about the global solar market, which accounts for a power of $30 \mathrm{GW}$ a year and growing. According to market research [15], in 2020, the five biggest inverter manufacturers were: first-Huawei, secondSungrow, third-SMA, fourth-Power Electronics (Freesun) and fifth-Fimeras. During the data collecting period from 1 February 2020 to 31 March 2020, 1008 pieces of documents were posted with the keyword "inverter" in English on different platforms, with the biggest share of Twitter, microblogs and news sites (data collection was made by TAD Consulting Ltd. through datastreamer.org). The result showed that the order did not follow the global share, as can be seen in Figure 4, which can be the result of brand marketing and the English language based dataset.

The sentiment analysis was made by using the NLTK tool [16], which is a leading platform for building Python programs to work with human language data. It provides interfaces to over 50 corpora and lexical resources, along with a suite of text processing libraries for classification, tokenization, stemming, tagging, parsing, and semantic reasoning, as well as wrappers for industrial-strength NLP libraries.

Documents with available localization data can even be visualized on a map (Figure 5) to demonstrate the possibilities of a local investigation. Unfortunately, not all documents were provided with geotags; therefore, it is a reasonable idea to work with larger datasets. 


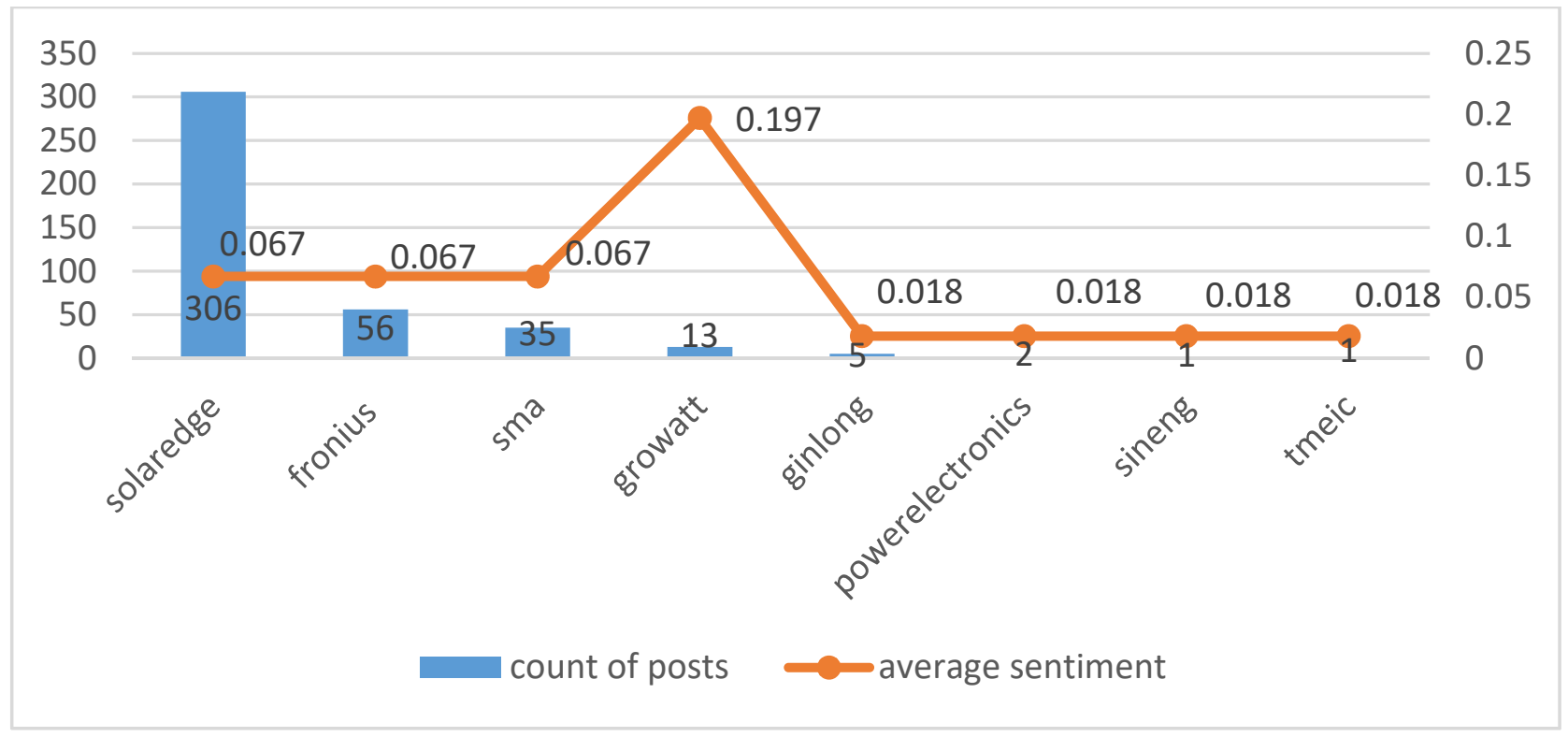

Figure 4. The number of posts and the average sentiments expressed in the posts.

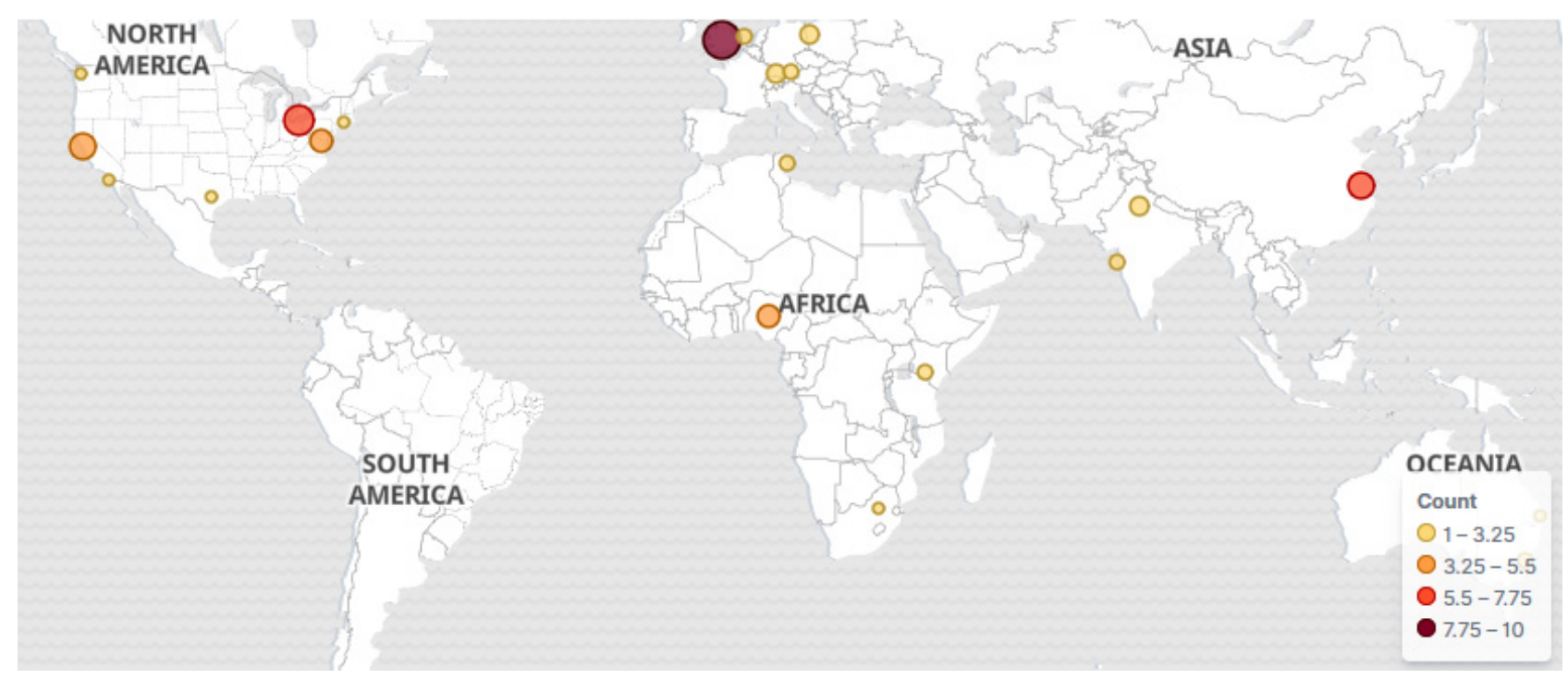

Figure 5. The map of the world with the origins of posts on PV inverters.

To verify the results, a test was carried out by using Google Trends, which showed the average number of hits for worldwide searches as follows: Fronius with 77, Growatt-49, and Solaredge with 47 hits, for one year back from September 2020, shown in weekly averages. Figure 6 shows the results of global and Hungarian average searches in a week. This differs from the social media research greatly, since here only conclusions about popularity can be made. 


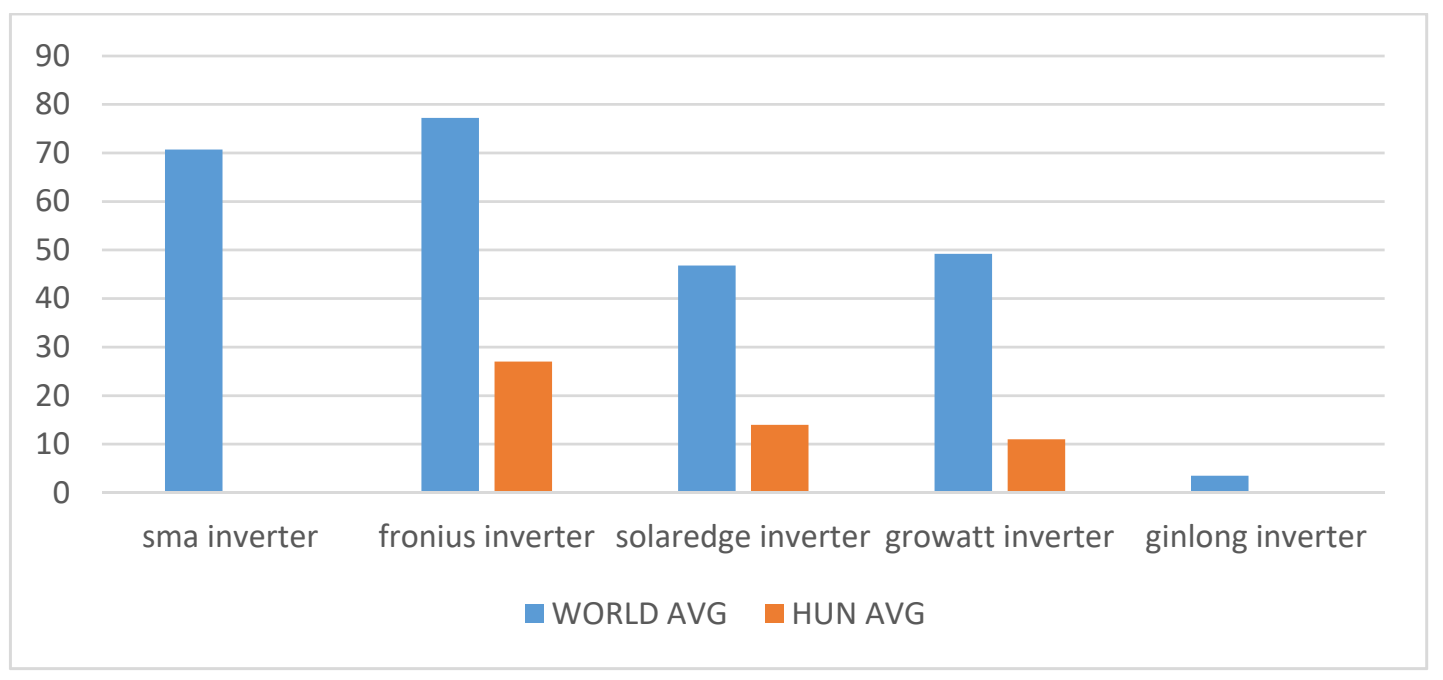

Figure 6. The average weekly number of global and Hungarian searches.

To examine the social media and the additional sources concerning the public acceptance of new technologies related to RESs and energy transition, data collection was carried out with the following search terms in English: ((solar AND (storage OR battery)) OR (photovoltaic AND (storage OR battery)) OR (pv AND (storage OR battery))) in the period from 1 February 2020 to 31 March 2020. It was possible to narrow down searches for Hungary, but it was not possible to include Facebook in this search, where the local citizens are more active than on Twitter, so it would result in a low document count. Facebook data were handled separately as follows in next su-chapter. In this dataset, 29,988 pieces of posts can be found, divided by five main domains shown in Figure 7.

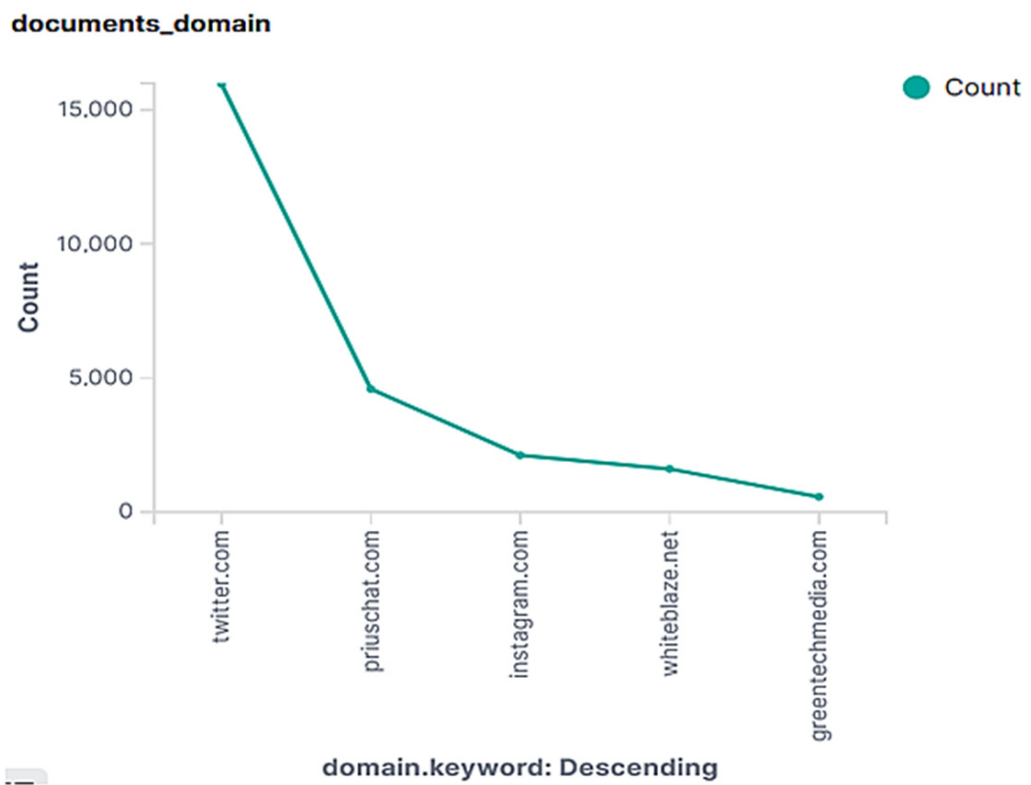

Figure 7. Main distribution of sources at technology analysis (storage systems).

From this dataset, the main manufacturers for solar battery package were chosen, based on Statista [17]. Since one of the most relevant topics of energy transition is storing the surplus energy and balancing the network, it could be very important to know what the consumers' opinion about energy storage is. The biggest manufacturers will lead the transition as suppliers for automotive industry, as manufacturers of industrial battery islands and as producers of home storage systems for distributed storage. The current state 
of popularity of the makers can be derived from this $30 \mathrm{~K}$ element dataset. As it can be seen in Figure 8, according to mentions, "Tesla" (with Powerwall) has the advantage of popularity over the others, but the sentiment score, i.e., satisfaction, leader is Victron (NL).

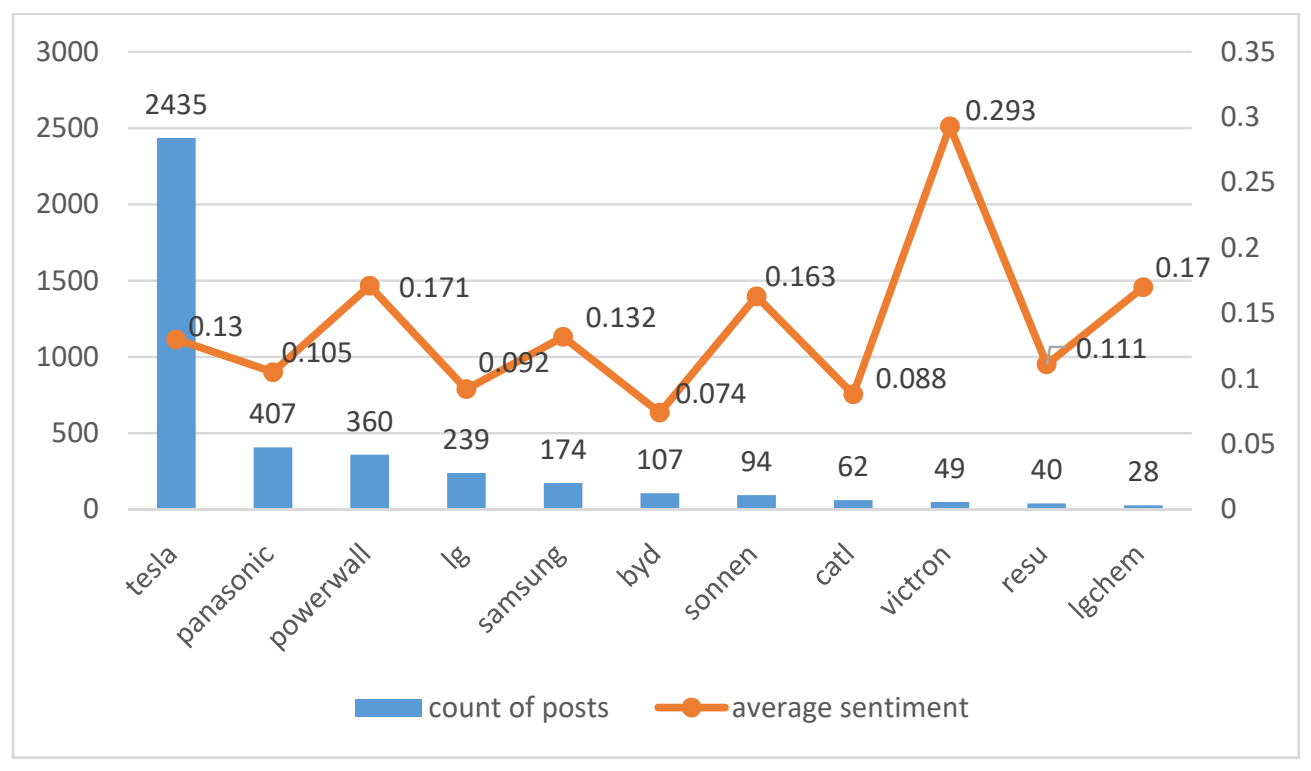

Figure 8. Number of mentions of the biggest battery manufacturers and their sentiment scores.

In our previous work, the European battery market was examined in 2018 [18], where the leading technologies were highlighted from multiple side (cost, energy density, etc.). Now, these technologies can be examined in the same previous dataset, in terms of popularity, satisfaction, with the results in Figure 9.

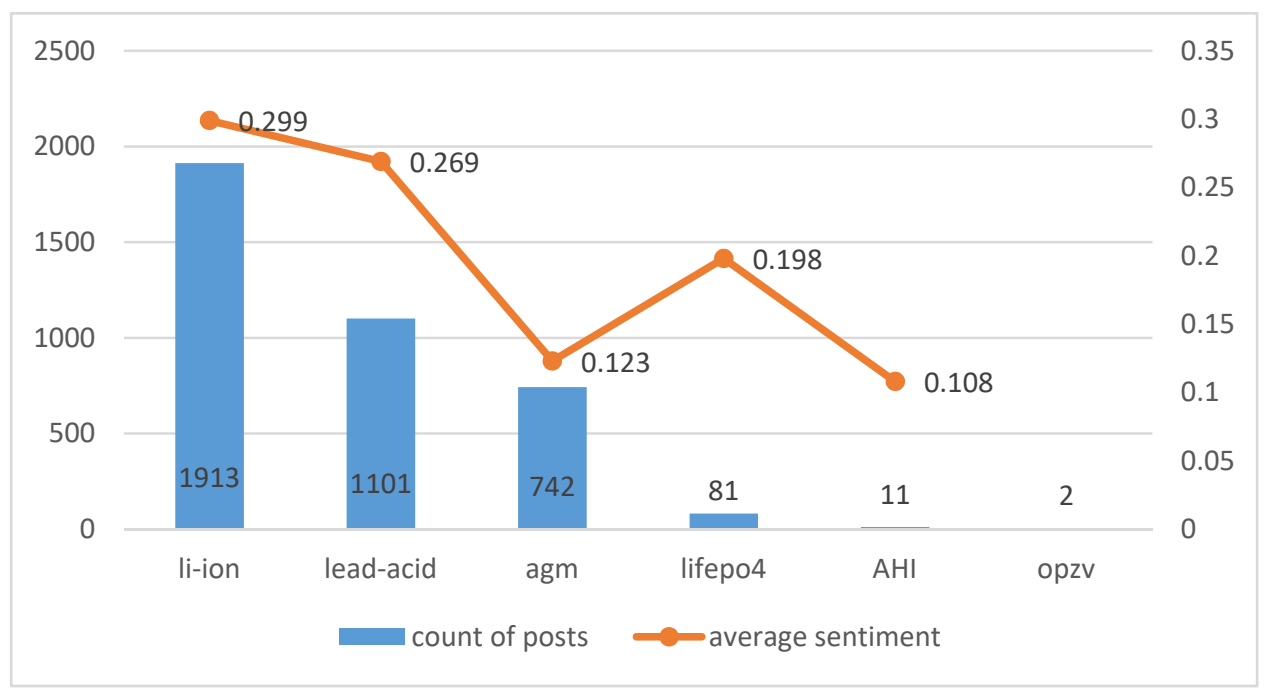

Figure 9. Number of mentions of the trending battery technologies and their sentiment scores.

In that study, the following PV battery technologies were analyzed asthey are easily accessible to the public [18]:

- Absorbent Glass Mat (AGM);

- Aqueous Hybrid Ion, AHI-salt water;

- Lithium-Ion, Li-ion (lithium manganese oxide, nickel-cobalt manganese or lithiumnickel-manganese-cobalt oxide);

- $\quad$ Lithium-Iron-Phosphate, $\mathrm{LiFePO}$; 
- Olivine-type-Lithium-Iron-Phosphate, Olivine-type-LiFePO4;

- Vented lead-acid battery, OPzS;

- $\quad$ Sealed lead-acid battery, OPzV.

Not all the technologies could be found in the dataset, which shows a lack of interest in these types.

Here, Lithium-ion technology has the widest popularity but surprisingly lead-acid and AGM are not much behind. This can be explained by the dataset focusing on solar storage, where mass and energy density are not very important. According to the previous study [18], AGM has a significant service cost during its lifetime, which can confirm its low sentiment level.

\subsection{Possible Method of Social Media Analysis Based on Target Groups}

The same SmapWorks ecosystem based data mining from the Facebook social media platform was implemented using scraper technology, in the Python programming environment. This was aided by the Ultimate Facebook Scraper software package [19], where information, posts and comments were processed from public groups. The resulting data were processed using gender resolution [20] and sentiment analysis [16] with the NLTK tool. The resulting dataset was indexed into ElasticSearch, for that scripts were created in a Python environment. With the tools created in this way, the Ad-VitalisLtd.'s SmapWorks data visualization platform provided assistance in data visualization and analysis. To monitor target groups, where professionals and competent people discuss their opinions about RESs (or subtopics such as energy transition or e-vehicles), popular and large groups need to be identified, where a large count of posts can be analyzed.

As a proof of concept, one large German group was selected with the topic "energiewende", which is about energy transition. In the Hungarian language, no target group was found, which can show a lack of interest at the present time, but in the future they will surely engage when this topic comes into people's daily life. The aim of the analysis of this dataset is similar to Q12 and Q13 in the II./E section, which was set to unveil the popularity and expectations on future technologies. We call "Energy transition" the process where renewable energies have to become even more integrated in the energy share of a country. The aim is to reach $60 \%$ of renewable generation and cut $\mathrm{CO}_{2}$ emissions by $80 \%$ relative to 1990. This can only be achieved by stopping using coal and natural gas and turning to renewables (solar, wind), biomass and waste thermal processing. However, it can only be reached, if it can be succeeded to store energy in TW scale. The following figure (Figure 10) shows terms in the "Energiewende" dataset related to the energy transition. Since it was a relatively small dataset, with 545 posts downloaded from the group, there are only few appearances of RES terms. Additionally, it can be very informative that the term itself comes out in a low score text environment, since its sentiment score is the lowest in the row with -0.037 .

Since the dataset of "Energiewende" even in Germany has a small number of posts, sentiment scores can not be representative in all cases, therefore an another source was also taken as reference for this type of public analysis for evaluation of the proof of concept.

A Hungarian open group was processed regarding Hungarian Oil company's (MOL) LIMO car sharing service, with 4733 downloaded comments, dating back 14 months. The analysis of this target group of electric vehicles could give a deeper insight into the technology but the word count showed that more mentions can be found related to the vehicle brands. Therefore, in addition to the technology sentiment score (electric, battery, range), the specific brand and competitor sentiments were processed. Fact is, that the MOL Limo service provides 450 cars-of them 150 were electric cars of three types (BMW i3, Smart EQ, VW eUp). This presents a great possibility to compare the electric car types based on the sentiment of the post in which it was mentioned (Figure 11). 


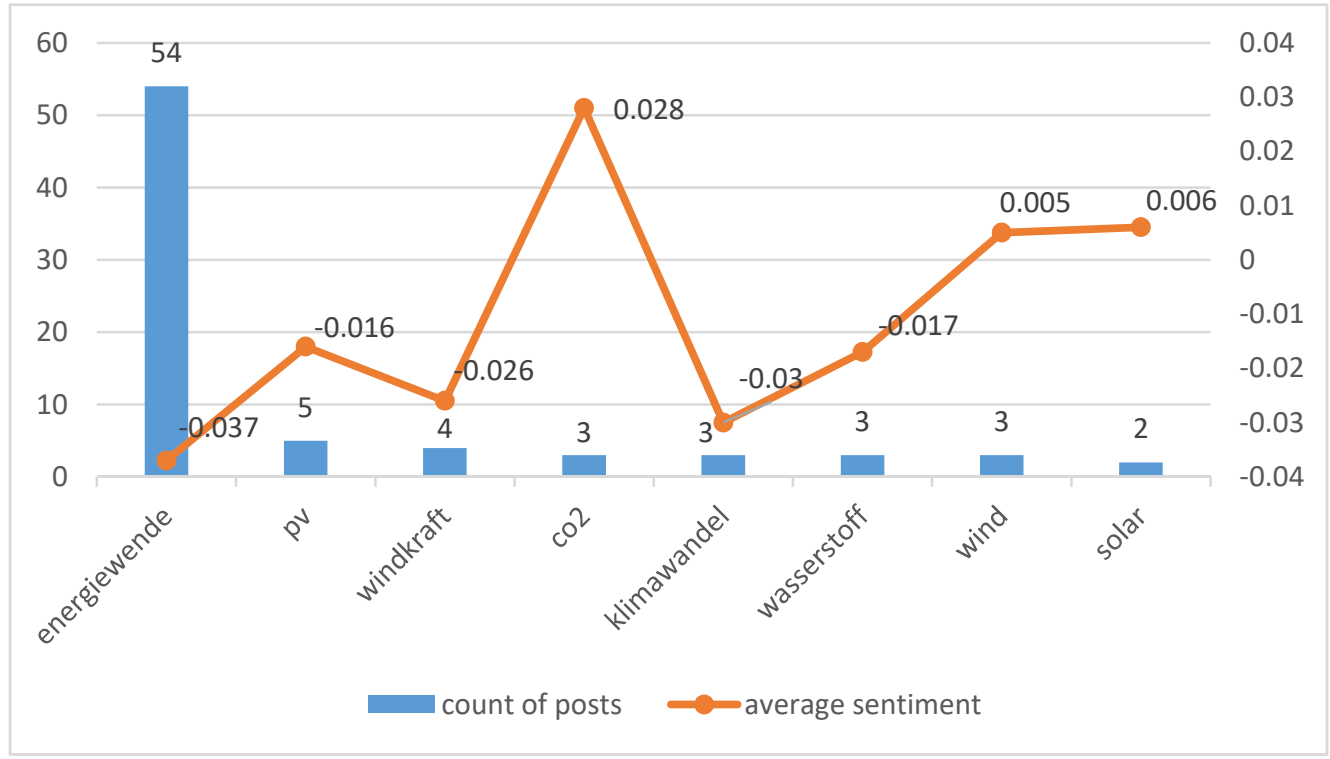

Figure 10. Analysis of the German group named "Energiewende".

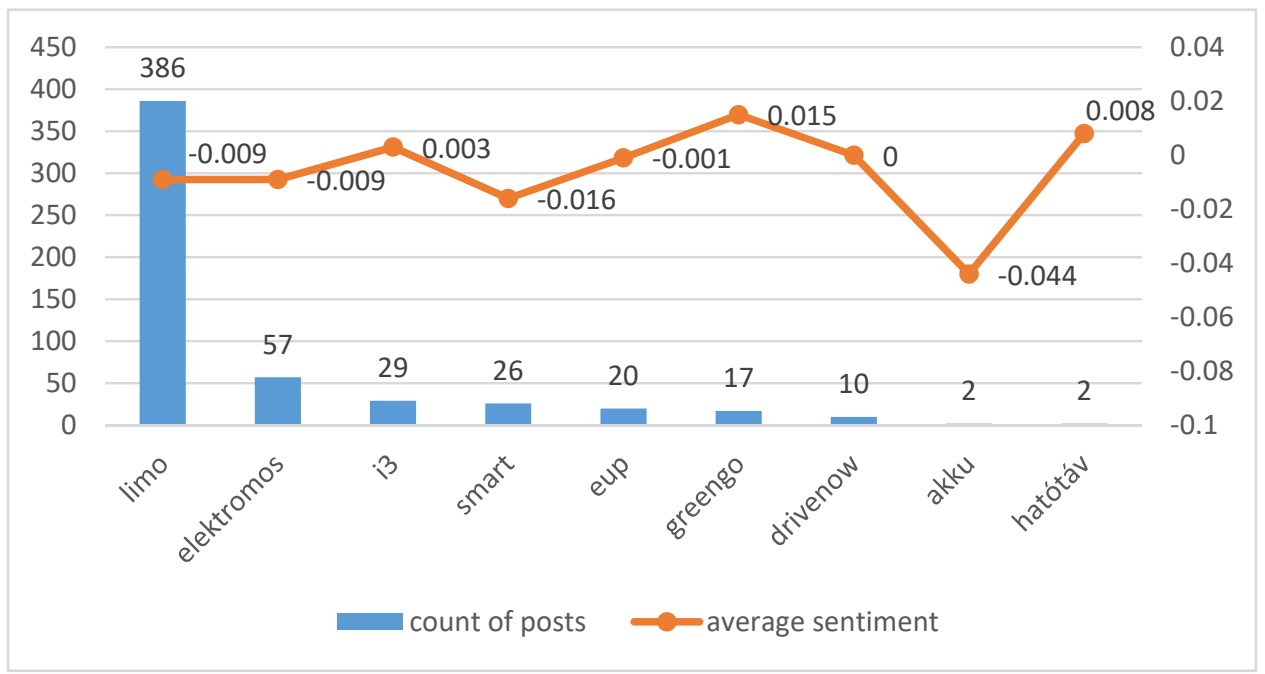

Figure 11. Number of mentions of terms in MOL car sharing Facebook group and their sentiment scores.

In the figure of the car types (i3, smart, e-up), two competitor companies to MOL Limo from Budapest (Greengo and Drivenow) and some terms (translation: elekromos-electric, akku, akkumulátor—battery, hatótáv—range) are highlighted. It can be seen that, from the electric cars, the BMW i3 has the highest popularity and acceptance, while the others are not much below. The mention of "Limo" - as the brand itself-has a sentiment score of -0.009 , while the competitors have higher rankings. All the data were influenced by the group itself; in the competitors group, the Limo would most likely have a higher score.

\subsection{Standard Social Media Monitoring Proposal in the RES Topic}

According to the introduced methods, the following social media monitoring standard proposal can be made for RESs, based on four steps (showed at the beginning of Section 3).

1. Data source and integration:

- Data source is individual, based on topic behalf of RESs:

i. Wide sources of news portals, blogs, Twitter, Facebook; accessed with term filtered query; 
ii. Target groups of specific topics from Facebook and/or with Twitter hashtag.

- Google Trends can be used to help identify terms for data query;

- Collection of data serialized, possibly json (can be automatized);

- Migrate data into ElasticSearch database.

2. Quantify data:

- Summarization of tags is provided in ElasticSearch;

- Word count, based on using include-and exclude dictionary.

3. Sentiment analysis:

- Using NLTK as a widely accepted NLP tool with support of over 50 languages to extract sentiment score.

4. Visualization:

- Visualization based on OpenDistro, a free front-end for ElasticSearch.

The pros of this method are that it only includes free tools such as ElasticSearch, NLTK, OpenDistro, where all these have strong research backgrounds, user popularity and many descriptions, and finally the results are fully comparable using them. The cons are that setting up a working system requires technical knowledge, especially in collecting and migrating datasets into the system, but there are already existing solutions, as it was shown in this case. Additionally, NLTK is a general language processing tool that can generate sentiment analysis, without any deep knowledge, and produce comparable results. To ensure more sophisticated results, it could be extended with energy related corpora and shared with the community, to use as standard in language processing in RES datasets.

\section{Conclusions}

Huge datasets are being generated continuously by social media and these kinds of solutions can provide a business intelligence method with real time brand monitoring, alerting and limitless processing with visualization.

In this study, two different methods with three different data sources were introduced for public knowledge, popularity and satisfaction estimation on RES related topics. A total of 716 answers were received for the survey, which shows the public acceptance and the understanding of the wide population about RES related novel technologies. Moreover, based on the previously collected information, social media research was conducted assessing the most popular technology related topics, which also covers product types, specifications. The possibilities of this Big Data system goes beyond the function of a classic survey, but it is shown here that different types of investigations can be made, with different conclusions.

The first method (the survey) uncovered the Hungarian public relations to RESs and it was compared to a Czech survey with the same questions. Statements have been made by comparing the two countries, which show different opinionson RESs. In light of the answers, strong actions should be taken in government communication, but it can also be stated that people do believe that future technologies of RESs can replace carbon based technologies.

The second method with two different data sources has revealed the limits of a smart Big Data system, which conductsfully automatic data collection, language interpretation with NLP and otherthings such as geological location visualization or gender designationpossible.

As the result of the different public opinion monitoring methods, the share of the opinion for a representative population sample related to theRES topic can be provided and, through social media analysis (SMA), the research can go deeper to monitor specified groups after interest, age, education, etc. Public opinion polls are standardized, they have to meet special rules to qualify them as representative but there is no standardization insocial media research and sentiment analysis yet. Although the investigated methods are connectedas they arebased on the topic of RESs, SMA alsohaslimitations (the targeting method, the limited count of target groups, accessing opinions based on interest), and sopublic surveysshould not be neglected. The currentstudy therefore covers a method for standardization of this process. 
Author Contributions: Conceptualization, methodology, visualization and writing, I.E.H.; data collecting, software and programming, M.T., K.H., R.H.; proofreading, assistance, G.P. All authors have read and agreed to the published version of the manuscript.

Funding: This research was funded by the 2019-LPP2-006 INTERREG B-LIGHT program.

Institutional Review Board Statement: Not applicable.

Informed Consent Statement: Not applicable.

Data Availability Statement: Anonym dataset of the public survey can be accessed on the following link: https:/ / docs.google.com/forms/d/1hpM4pJgqs6Etf1eIB27mq4aj-BKwgadsW6_gj6XV0Bs / (accessed on 11 May 2020).

Conflicts of Interest: The authors declare no conflict of interest.

\section{References}

1. Available online: https: / /ec.europa.eu/eurostat/tgm/table.do?tab=table\&init=1\&language=de\&pcode=t2020_31\&plugin=1 (accessed on 11 May 2020).

2. Bouzarovski, S.; Herrero, S. The energy divide: Integrating energy transitions, regional in equalities and poverty trends in the European Union. Eur. Urban Reg. Stud. 2017, 24, 69-86. [CrossRef] [PubMed]

3. Li, R.; Crowe, J.; Leifer, D.; Zou, L.; Schoof, J. Beyond big data: Social media challenges and opportunities for understanding social perception of energy. Energy Res. Soc. Sci. 2019, 56, 1-14. [CrossRef]

4. Pacesila, M.; Burcea, S.; Colesca, S.E. Analysis of renewable energies in European Union. Renew. Sustain. Energy Rev. 2016, 56, 156-170. [CrossRef]

5. Čábelková, I.; Strielkowski, W.; Firsova, I.; Korovushkina, M. Public Acceptance of Renewable Energy Sources: A Case Study from the Czech Republic. Energies 2020, 13, 1742. [CrossRef]

6. Heras-Saizarbitoria, I.; Cilleruelo, E.; Zamanillo, I. Public acceptance of renewables and the media: Ananalysis of the Spanish PV solar experience. Renew. Sustain. Energy Rev. 2011, 15, 4685-4696. [CrossRef]

7. Szabo, L.; Bartek-Lesi, M.; Diallo, A.; Kerekes, L. Nemzeti Energiastrategia Ertekelese REKK Study. Available online: https: //rekk.hu/downloads/academic_publications/rekk_policybrief_hu_2020_02.pdf (accessed on 11 May 2021).

8. Ribeiro, F.; Ferreira, P.; Araújo, M.; Braga, A. Public opinion on renewable energy technologies in Portugal. Energy 2014, 69, 39-50. [CrossRef]

9. Zoellner, J.; Schweizer-Ries, P.; Wemheuer, C. Public acceptance of renewable energies: Results from case studies in Germany. Energy Policy 2008, 36, 4136-4141. [CrossRef]

10. Hondo, H.; Baba, K. Socio-psychological impacts of the introduction of energy technologies: Change in environmental behavior of housholds with photovoltaic systems. Appl. Energy 2010, 87, 229-235. [CrossRef]

11. Kim, Y.; Kim, M.; Kim, W. Effect of the Fukushima nuclear disaster on global public acceptance of nuclear energy. Energy Policy 2013, 61, 822-828. [CrossRef]

12. Jain, A.; Jain, V. Sentiment classification of twitter data belonging to renewable energy using machine learning. J. Inf. Optim. Sci. 2019, 40, 521-533. [CrossRef]

13. Reboredo, J.C.; Ugolini, A. The impact of Twitter sentiment on renewable energy stocks. Energy Econ. 2018, 76, 153-169. [CrossRef]

14. Loureiro, M.L.; Allo, M. Sensing climate change and energy issues: Sentiment and emotion analysis with social media inthe U.K. and Spain. Energy Policy 2020, 143, 111490. [CrossRef]

15. Mackenzie, W. Inverter MarketShare. 2020. Available online: https://www.woodmac.com/our-expertise/focus/Power-Renewables/inverter-market-share-2020/ (accessed on 11 May 2020).

16. Available online: https://www.nltk.org/api/nltk.sentiment.html (accessed on 11 May 2020).

17. Available online: https://www.statista.com/statistics/235323/lithium-batteries-top-manufacturers/ (accessed on 11 May 2020).

18. Zsiborács, H.; Baranyai, N.; Vincze, A.; Háber, I.; Pintér, G. Economic and Technical Aspects of Flexible Storage Photovoltaic Systems in Europe. Energies 2018, 11, 1445. [CrossRef]

19. Available online: https://github.com/harismuneer/Ultimate-Facebook-Scraper (accessed on 11 May 2020).

20. Available online: https://pypi.org/project/gender-guesser/ (accessed on 11 May 2020). 